\title{
Apuntes
}

\section{Vías Verdes en Andalucía}

\author{
Carmen Aycart Luengo \\ Directora del Programa Vias Verdes \\ Fundación de los Ferrocarriles Españoles
}

Las Vias Verdes son antiguos trazados ferroviarios en desuso acondicionados como infraestructuras para desplazamientos no motorizados, dotadas de cualidades especificas: máxima accesibilidad, facilidad y seguridad, por lo cual son lugares especialmente atractivos para personas con movilidad reducida (niños, ancianos, minusválidos). En la actualidad existen en toda España 1.350 kilómetros de Vías Verdes operativas (366 de ellos en Andalucia), desarrollados en el marco del Programa coordinado por la Fundación de los Ferrocarriles Españoles (FFE) y liderados por el Ministerio de Medio Ambiente, con la colaboración del Administrador de Infraestructuras Ferroviarias y RENFE Operadora (estos son los dos entes nacidos en enero de 2005 de la anterior RENFE), Feve, Comunidades Autónomas, Diputaciones y Ayuntamientos.

El programa de reutilización de infraestructuras ferroviarias fuera de servicio se inició en 1993, año en el que la FFE elaboró un Inventario de Líneas Ferroviarias en Desuso, por encargo del entonces Ministerio de Obras Públicas, Transportes y Medio Ambiente (Moptma), Renfe y Feve. Fue elaborado por un equipo multidisciplinar de técnicos que recogió datos, tanto sobre la infraestructura ferroviaria y los inmuebles, su situación patrimonial y estado de conservación, como respecto al entorno social, natural y cultural de los municipios atravesados. La investigación permitió, además, establecer un primer contacto con más de un millar de ayuntamientos a los que se solicitó información sobre el estado de conservación de este patrimonio y sobre sus proyectos de recuperación.

Se identificaron y analizaron en detalle 98 líneas ferroviarias en desuso o con débil tráfico que dependian de los tres entes que encargaron el inventario, y que sumaban una longitud total de $5.764 \mathrm{~km}$, incluyendo un impresionante patrimonio de gran valor: 954 estaciones, 501 túneles y 1.070 puentes y viaductos. De esta longitud, $1.442 \mathrm{~km}$ discurrian por tierras andaluzas, lo cual representaba un importante porcentaje del total, un 25,4\%. Adicionalmente, se recopilaron datos relativos a otras 89 líneas ferroviarias de tráfico minero e industrial, de carácter privado, que totalizaban $1.920 \mathrm{~km}$. Sobre esta impresionante malla de ferrocarriles abandonados (¡casi 8.000 kilómetros!) que tejían el territorio sin uso alguno, se ha ido desarrollando el Programa Vías Verdes, siendo Andalucía una de las Comunidades donde mayor implantación tiene.

En el mapa (imagen 4) se refleja la situación de las Vías Verdes operativas en la primavera de 2005, así como los trazados ferroviarios que, sin haber sido rehabilitados aún, son transitables para ciclistas y caminantes. En la Comunidad Autónoma de Andalucia existen 366 km de Vías Verdes plenamente acondicionadas (ver tabla 1), existiendo además diversos proyectos redactados que previsiblemente serán ejecutados en 2006 y 2007. Existe amplia información sobre estos itinerarios andaluces en la
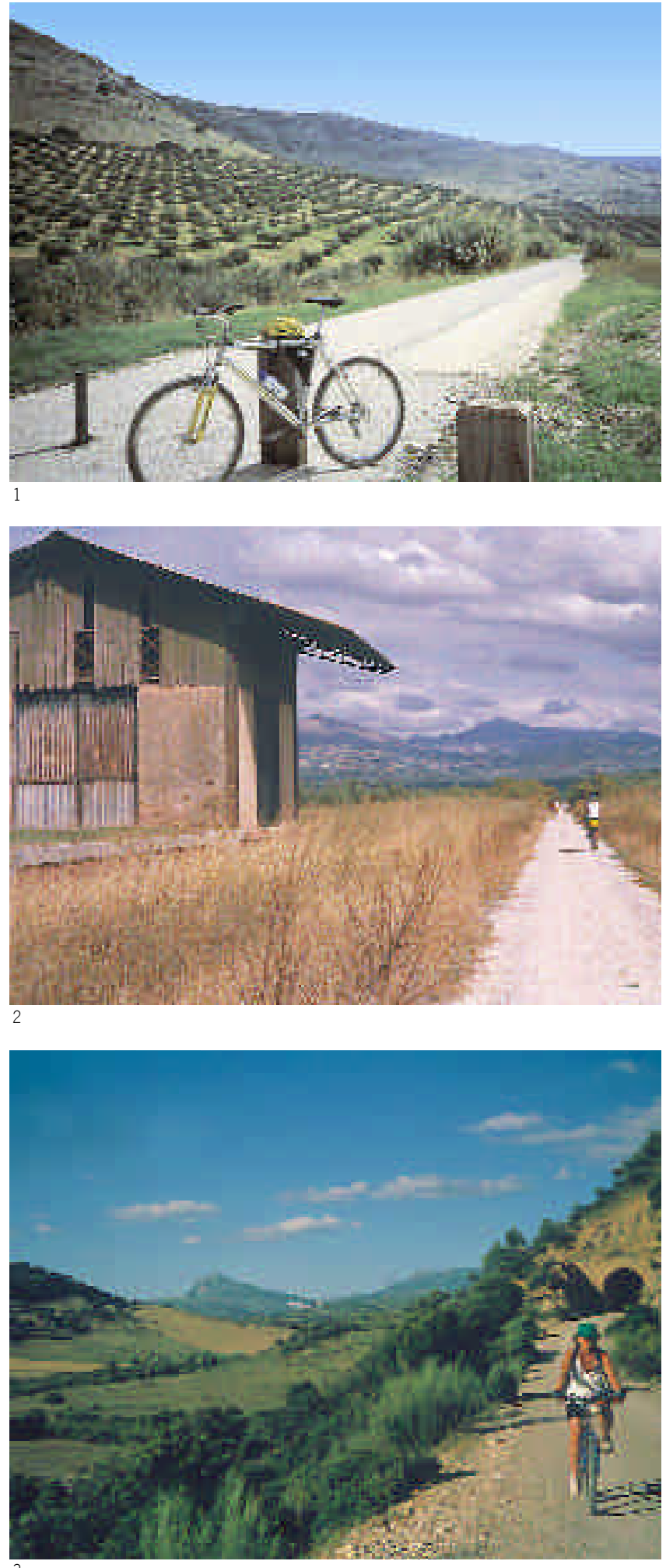


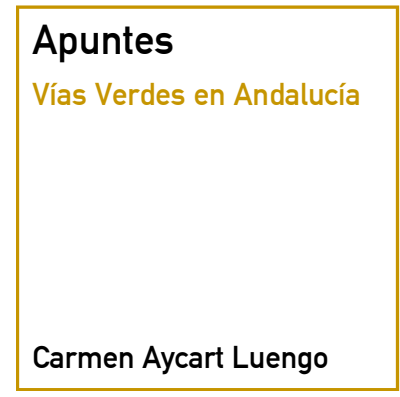

1 y 2. Vía Verde del Aceite (Córdoba-Jaén). Fuente: Fundación de los Ferrocarriles Españoles

3. Via Verde de la Sierra (Sevilla-Cádiz). Fuente: Fundación de los Ferrocarriles Españoles

4. Mapa de Vias Verdes. Fuente: Fundación de los Ferrocarriles Españoles

\begin{tabular}{|c|c|c|}
\hline Tabla 1. Vias Verdes operativas en Andalucia, 1993 - 2005 & Provincia & Longitud (Km) \\
\hline Vía Verde de La Sierra & Cádiz - Sevilla & 38 \\
\hline Vía Verde de la Rivera del Huéznar & Sevilla & 18 \\
\hline Vía Verde de la Campiña* & Córdoba - Sevilla & 91 \\
\hline Vía Verde de Linares & Jaén & 6 \\
\hline Vía Verde del Aceite & Jaén & 55 \\
\hline Vía Verde de la Subbética & Córdoba & 56 \\
\hline Vía Verde del Guadiana & Huelva & 17 \\
\hline Vía Verde de los Molinos del Agua & Huelva & 36 \\
\hline Via Verde del Litoral & Huelva & 49 \\
\hline Total & & 366 \\
\hline
\end{tabular}

Guía de Vías Verdes (2 vols.) publicada por la FFE en la editorial Anaya, así como en la web de la FFE (www.viasverdes.com) y en el Mapa Oficial de Carreteras del Ministerio de Fomento. Y será posible conocerlos con más detalle a través de la serie de televisión "Vive la Vía" que ha realizado la FFE y que está siendo emitida por La 2 de TVE desde mediados de septiembre de 2005 (11 capítulos de 30 minutos, los domingos noche), en donde se incluyen tres capitulos sobre Vias Verdes andaluzas.

Las Vias Verdes españolas se han convertido en un referente para iniciativas similares a nivel internacional. Ha recibido algunos reconocimientos de gran prestigio, entre los cuales es obligado mencionar el Premio Internacional de Buenas Prácticas del Programa Habitat de la Organización de Naciones Unidas (año 2000) y el Premio Europa Nostra, con una Medalla en la categoría "Dedicación a la Conservación del Patrimonio" (año 2004). Además, la FFE es socia fundadora de la Asociación Europea de Vias Verdes, cuya presidencia ha desempañado desde su creación en 1998 hasta 2004.

Los principios básicos del Programa Vías Verdes son la reutilización con fines sociales y ambientales de las líneas ferroviarias en desuso, preservando el patrimonio histórico ferroviario y garantizando el dominio público sobre él, impulsando actividades de turismo ecológico y activo que promuevan el empleo local en las zonas atravesadas. Es importante, en este sentido, la rehabilitación de edificaciones ferroviarias para crear equipamientos para los nuevos visitantes (hoteles, restaurantes...). Al tiempo, las Vias Verdes impulsan un cambio de mentalidad en los ciudadanos hacia formas de movilidad sostenible y hábitos de vida más saludables.

El Programa español de Vías Verdes confiere una imagen global y homogénea a cada Vía Verde, bajo la cobertura de un logotipo único y general, y de una señalización diseñada expresamente para ellas, lo cual refuerza este concepto de identidad nacional, como producto diferenciado y de calidad. Esta imagen identificativa se vincula siempre al origen ferroviario de las Vías Verdes, utilizándose diseños y materiales que preservan esta memoria histórica.

\section{VIAS VERDES EN ESPAÑA}

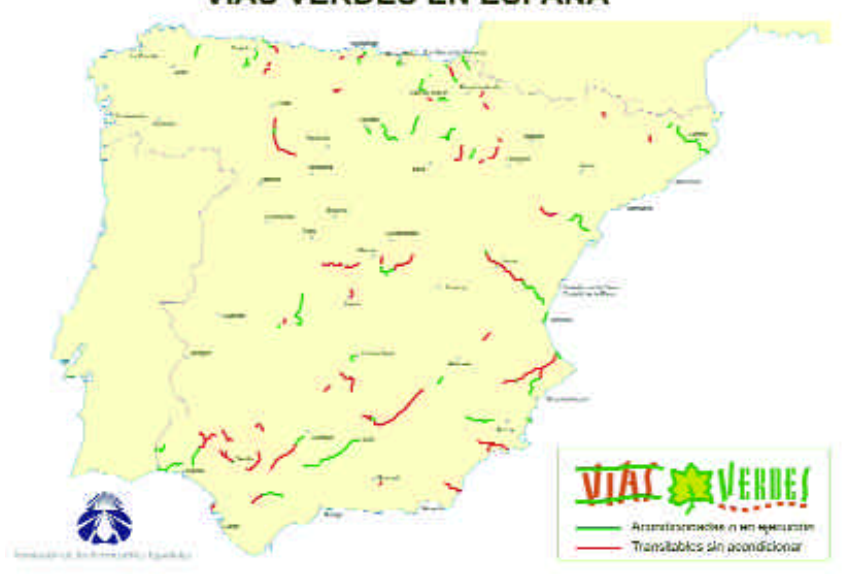

